\title{
Usage of Internet in the Process of Education
}

\author{
Radovan Antonijević \\ University of Belgrade, Faculty of Philosophy
}

Received 15 September 2018 - Revised 20 December 2018 • Accepted 25 December 2018

\begin{abstract}
The Internet represents unavoidable source for different knowledge and information, for using in professional and personal learning purposes. Based on this fact, accessibility, richness and diversity of the contents in each domain make the key characteristics of the Internet. By the development of the Internet, a new phenomenon is included in the field of education, phenomenon of learning via Web, or online learning. Besides different models of learning applied in the process of institutional education, learning via Web offers opportunities for purposeful and systematic enrichment of the process of education, which can significantly enable higher level of students' achievement quality in any field of teaching and learning. However, all contents of the Internet has no the same importance for the process of education. For example, contents exposed by scientific and educational institutions have scientific and educational basement in the same time, as their inner essential characteristics. The other different contents, transferred on the Internet by the other institutions and individuals, don't possess necessarily scientific and educational basement and importance. In this work we will discuss the following characteristics of the Internet, significant for the process of education: (1) diversity of the Internet contents, (2) accessibility of information via Internet, (3) characteristics of the Internet communications, and (4) characteristics of the interactions via Internet.
\end{abstract}

Keywords: Internet, process of education, distance education, Internet communication, Internet interaction.

\section{Introduction}

As the most sophisticated and effective way of communication in the modern world, the Internet has become part of the modern human reality. Nowadays, it is almost unavoidable to effectively work in a workplace of any profession that requires a high level of education and competence, without using this irreplaceable communication and learning resource. Efficiency in the performance of any profession directly depends on the way and available opportunities that are used over the Internet. Everyday life of each individual is also under the great influence of various technical possibilities and learning potentials provided by the Internet. In the modern world, the Internet has become the primary means of communication between individuals, institutions, organizations etc., a means of education, learning and entertainment. In the fields of professional and everyday life usage, the Internet is very widely used.

In a technical sense, the Internet represents a global system of interconnected computer networks, through which data are exchanged. It is also referred to as the "network of networks", consisting of millions of private, public, academic, business, government, and nongovernment networks around the world, based on various technological solutions. This global

(C) Authors. Terms and conditions of Creative Commons Attribution 4.0 International (CC BY 4.0) apply. Correspondence: Radovan Antonijević, University of Belgrade, Faculty of Philosophy, Čika Ljubina 1820, 11000 Beograd, SERBIA. E-mail: aa_radovan@yahoo.com. 
network serves as the basis for various resources or possibilities of the Internet, such as web communication (www), email (e-mail), "chat" on the Internet (online chat), video communication, file sharing, online gaming, and so on. The Internet is a complex conglomerate of various systems and subsystems, connected in a comprehensive network structure. It is, in itself, the most complex system that man ever created, with the tendency of further extending and improving different structures and functional connections, applying new technological possibilities and solutions. This is also facilitated by new data transmission technologies over the Internet and constantly increasing of the speed of connections and data flow in both directions (transfer, download and upload).

What are the basic characteristics of the Internet? What is the importance of the Internet for an organized, systematic and purposeful activity such as education and education? Which educational and other influences can be achieved through the Internet? Also, in what ways can the Internet be used for educational purposes, in order to make this process more efficient? These are some of the important issues that pedagogy as the science of education should seek adequate responses and improve knowledge in this area.

There are a number of different general and specific characteristics of the Internet, ranging from the level of technological-technical solutions to the level of highly sophisticated communication models on the Internet, which are performed with complex software. This is reflected in a wide range of possibilities for using the Internet for various purposes, and consequently in the field of realization of the process of education and for learning purposes. For many years, the Internet has been used for educational purposes, that is, it can be said that it has been put into the function of education and learning (Dogruer, Eyyam \& Menevis, 2011). From the very beginning of the development of Internet, it has been established that some of the opportunities offered by Internet can be applied in the process of education and that in this way the organization and process of realization of education at all levels in which it is organized and conducted, can be significantly improved. With the development of the Internet, the level of application of its capabilities in the process of education has been gradually increased, with a wide scope for further introduction of new and more expedient use of existing Internet capabilities in this area.

One of the areas of education, which owes its more intensive and more complete development, as well as the expansion in today's time based on the development of the Internet, is the field of distance education (Moore \& Kearsley, 2005). In addition to the term "distance education", in pedagogical theory and practice, concepts such as "distance learning", "online education", "online learning", "e-learning” and other concepts (Moore, Dickson-Deane, \& Galyen, 2011), to a greater or lesser extent, coincide with the scope and content of the general term "distance education" or belong to it as part of the content. The term "online" means the situation of an active computer connection to the Internet, and in this case, "online education" and "online learning" mean the use of a computer connected to the Internet in the distance learning process.

The essence of distance education is to provide educational opportunities for people who are not able to be physically present at the place where education is organized within a particular institution (Moore \& Kearsley, 2005), or who are physically distant from an institution that provides educational opportunities remotely, in the form of a long distance education program. This field of education is particularly suitable for further education, post-secondary nontertiary education, as well as for the design of different models of adult education. In the practice of the realization of distance education programs, it has been proven that good results can be achieved precisely in the field of adult education, which is designed for different purposes (professional development, acquiring a vocation outside the profession, acquiring a higher level of education, etc.). The field of distance education is appropriate for some fields of economy, for persons who, on the basis of their workplace nature, cannot be absent for the purpose of attaining a higher level of education. Different opportunities in the field of distance education are also 
provided to persons employed in the military, police and similar services, who are also not able to participate directly in the process of implementing conventional education programs.

Based on the above, we can also talk about certain content of education that can take place over the Internet. However, in such a situational definition of education, it is necessary to start from the very definition of education, in order to separate the influences and activities that belong to the field of education through the Internet, from those who do not belong to that field. If education implies a system of planned, intentional (aim-oriented), organized, and systematic influences on the development of an individual as a whole, then the elements of education over the Internet can be considered only those effects on individuals who are planned, intentional, organized and systematic. So, these would be those influences that are designed and organized with the purpose of achieving certain educational goals (Dogruer, Eyyam \& Menevis, 2011). In this way, a key difference is seen in relation to most other "influences" on an individual that come over the Internet, but which cannot be subsumed under area of education. For example, when an individual finds on the Internet contents that will have a certain impact on him/her, in a wider socialization process, it is not education in the true sense of the term.

In the system of education, the Internet can be used at different levels within the system. Regardless of certain limitations in constituting the structure of the Internet usage level in the system of education and the seemingly patterned approach in the constitution of this structure, in this sense, the education system can be divided onto the following levels: (1) the level of the Ministry of Education, (2) the level of local governance, (3) the level of the organization of an educational institution, and (4) the level of realization of the process of education, teaching and learning. Without neglecting the importance of using the Internet in the first three levels within the education system, the science of education should pay particular attention to the level of Internet usage that relates to the organization and realization of the education process, with particular emphasis on the part of that process that takes place through teaching and learning.

Certain characteristics of the Internet are of the great importance for the realization of certain activities in the field of educational activities and the use of the Internet for this purpose. In this paper we deal with the following characteristics of the Internet, which are important for educational activity: (1) diversity of contents, (2) accessibility of information, (3) possibilities of effective communication, (4) diversity of interactions.

\section{Diversity of contents}

On the Internet, every person with a certain level of training, skill and resourcefulness can find everything that is necessary to perform a business task or a personal activity, in a quick and efficient way. With a certain level of systematic training for using the Internet, the scope of what can be found on the Internet is increasing significantly. The richness and diversity of contents in all areas of knowledge and entertainment is one of the key characteristics of the Internet. Different preferences and interests, as well as the curiosity of each individual, can be met on some part of the global network.

However, the fact is that not all contents on the Internet are equally accessible, valuable, and usable. Therefore, a certain level of training is required for the purposeful use of the diversity of contents provided by the Internet (Trexler, 2018), with the rational and cost-effective use of time spent on the Internet.

Contents that are posted by scientific institutions have scientific value and reliability. The various contents of these institutions are very useful materials that can be found on the Internet, and are of the great relevance to the academic public. These can be the following contents: texts from scientific journals (original scientific papers, review papers), scientific monographs or parts of monographs, scientific discussions, polemics and depictions, doctoral 
dissertations, descriptions of scientific projects, elaborates, analyzes, data bases, etc. Texts from scientific journals can be placed as electronic editions of scientific journals, or in the option of selected texts according to different selection criteria. Special significance has all contents which are enabled for audience in the mode of open access, which includes free access (access without paying) to scientific results published online.

The various national scientific institutions and non-governmental organizations, both nationally and internationally, have wide-ranging areas of comprehensive databases and electronic libraries, with the ability to access, search and download over the Internet. Some of these databases are DOAJ (https://doaj.org), EBSCO (http://search.ebscohost.com), ERIC (Educational Information Center - http://www.eric.ed.gov), Academic Search Premier and other services. Some of these electronic libraries have free access, and some are accessed with assigned username (password) access, which allows access only to registered users who are engaged in teaching-scientific activity at the university level. Common formats used for electronic publications of scientific works on the Internet are HTML (Hypertext Markup Language), PDF (Portable Document Format, with .pdf extension), MS Word format, with extensions .doc, .docx, .rtf, etc.

Unlike them, certain contents posted on the Internet by legal entities whose activity is not a matter of science or by individuals, does not necessarily have scientific value. When downloading such contents, it is necessary to have the precaution that should be expressed in relation to their credibility, correctness, accuracy, etc. However, these contents do not necessarily and a priori should be considered unusable, circumvented and rejected. On the contrary, the greatest amount of useful knowledge and information can be found in this sector on the Internet. On this basis, it is necessary to use knowledge and information from this sector, but by checking and verifying credibility of their sources.

\section{Accessibility of information}

In the period before the emergence and development of the Internet, one of the key problems in the use of knowledge and information was the problem of their accessibility. Access to different knowledge, content and information was generally limited by the technical capabilities of key mediators in the transmission of information that were predominant in a certain stage of the development of mass media, in the following line of appearance and development: printing, radio, television, satellite television, cable television, and so on. These various media in the exchange of information were various state, public and non-governmental institutions and organizations (libraries, cultural institutions, public information institutions, public services in different areas, etc.).

With the appearance and development of the Internet, the accessibility of information is drastically increased, regarding the amount of information that is constantly increasing. What inevitably follows a dramatic increase in the volume of information on the Internet is the need for information selection.

In spite of the fact that the volume and accessibility of information on the Internet has continued to increase, there has been a limited access to information from the very beginning of Internet's development in various areas, which is enabled to certain predefined categories of users. In addition, there are different levels of "confidentiality" of access. For example, the highest level of confidentiality would be the data stored in intelligence services' databases, if at all available on the Internet, with the highest level of access restriction (multiple levels of access protection). The restriction of access, as already described, also exists in the area of electronic editions of scientific papers published on the Internet, which can be accessed based on the user name and password, enabled by payment for the access. 


\section{Possibilities of effective communication}

Nowadays communication through the so-called "hard mail", or via classic postal items, is considered as slow and obsolete way of communication. In the initial phases of the development of distance education, the use of this type of communication took place to a large extent. In contrast, e-mail communication today is the predominant and maximally efficient form of communication, with numerous additional technical capabilities found in various e-mail communication software.

In addition to e-mail, the so-called chat communication has been developed on the Internet. This communication is provided with the help of the IRC (Internet Relay Chat) system and it implies the possibility of direct written communication between two or more persons over the Internet. The most famous services for this type of communication via Internet are MSN Messenger, Viber, ICQ and MIRC. In recent times, communication is evolved towards the integration of text, audio and video in communication (audio-visual conversation, or video phone). One of the newer software in this area (MSN Messenger), besides text, audio and video communication, enables the transfer of files, photos, links, etc. Of course, all of these forms of the Internet communication can be efficiently used in the process of education, teaching and learning.

\subsection{Variety of interactions on the Internet}

By looking at the basic possibilities of communication on the Internet and their basic characteristics, it can be seen that there are huge opportunities for diverse interaction over the Internet, which in itself points to the numerous possibilities of applying interactions over the Internet in the process of education (Internet Society, 2017). However, it is not possible to transfer all models of online interaction into the process of education, and in the same or similar way use them in the process education.

In the process of education, in addition to the individual activities, different forms of interaction also play an important role, enabling individuals to develop their abilities and skills through different activities and interactions. Interaction in the process of education can be a personalized and depersonalized interaction, and we have a similar situation when it comes to various forms of interaction that take place over the Internet.

Personalized interaction in the process of education is the form of interaction in which a student as an individual enters in an active relationship with other subjects of the process of education, with one or more individuals. Personalized interaction over the Internet is accomplished through various forms of interaction, such as student-student, teacher-student, student-student group, student group-student group, etc.

Depersonalized interaction in the process of education is the form of interaction of teachers and students with the physical environment in which the process of education takes place. For example, a student is in interaction in the flipped classroom with didactic material (Trexler, 2018), when he solves the task in the worksheets, when he builds the model of the house, when he constructs a given geometric form based on the available parameters, etc. In fact, various forms of depersonalized interaction can often appear in the classroom, and they are important for the development of different abilities and skills in students. There is a wide range of possibilities for the realization of various forms of depersonalized interaction over the Internet, and these possibilities should be purposefully used.

Also, it must be emphasized that there are certain forms of interaction in the process of education that cannot be enabled over the Internet, or can be enabled on a limited scale, which are important for the more efficient implementation of the process of education, teaching and learning. This applies, first of all, to the models of direct interaction, such as teacher-teacher, 
teacher-student, and student-student. Despite the fact that these interaction models can also be achieved in communication over the Internet, there are some limits because the fact that the characteristics of such interaction are conditioned by the lack of a complete direct contact between the subjects of interaction. Despite the fact, a teacher and student can communicate over the Internet and thus make interaction as a part of some learning activities.

\section{Conclusion}

Internet as a basic means of mass communication has a wide field of application, and it will increasingly gain in importance in the field of institutionalized and non-institutionalized education in the future. Some bold assumptions about the importance of the Internet in this area are aimed at predicting that the Internet will play a key role in this domain, which in particular refers to the emphasis on the importance of future distance education. The role of the Internet will increase in the future in all area of education, at all level of education, and also in domain of existing of different form of individual informal learning.

\section{Acknowledgements}

This work is a result of the project "Models of evaluation and strategies of improvement education quality in Serbia" (No. 179060, 2011-2018), financially supported by Ministry of Education, Science and Technological Development, Republic of Serbia.

The author declares no competing interests.

\section{References}

Dogruer, N., Eyyam, R., \& Menevis, I. (2011). The use of the Internet for educational purposes. Procedia Social and Behavioral Sciences, 28, 606-611.

Internet Society (2017). Internet access and education: Key considerations for policy makers. Retrieved 20 November 2018, from https://www.internetsociety.org/wpcontent/uploads/2017/11/Internet-Access-Education_2017120.pdf.

Moore, J. L., Dickson-Deane, C., \& Galyen, K. (2011). e-Learning, online learning, and distance learning environments: Are they the same? The Internet and Higher Education, 14, 129-135. http://doi.org/10.1016/j.iheduc.2010.10.001.

Moore, M. G. \& Kearsley, G. (2005). Distance education: A systems view (Second ed.). Belmont, CA: Wadsworth.

Traxler, J. (2018). Distance learning - Predictions and possibilities. Education Sciences, 8(35), 1-13. https://doi.org/10.3390/educsci8010035. 